\title{
A new behavioral test for assessment of drug effects on attentional performance and its validity in cynomolgus monkeys
}

\author{
Atsushi Fujiwara', Masahiko lino¹, Mikio Sasaki¹, Naoyuki Hironaka² and Yoshio Wakasa ${ }^{1}$
}

${ }^{1}$ Ina Research Inc., 2148-188 Nishiminowa, Ina, Nagano 399-4501, Japan

2 Shimojo Implicit Brain Function Project, ERATO, Japan Science and Technology Agency, 3-1 MorinoSato-Wakamiya, Atsugi, Kanagawa 243-1098, Japan

(Received November 10, 2008; Accepted December 22, 2008)

\begin{abstract}
The assessment of drug effects on attention is important in non-clinical pharmacology, for both evaluation of safety and therapeutic efficacy of medicinal products. In the present study, we have developed a two-lever choice behavioral test to assess drug effects on attentional performance in monkeys. In each trial of this experiment, one of two lamps in front of a monkey was randomly illuminated for a brief period of time and the monkey was required to press a lever beneath the lamp 30 times to obtain a food reward. The percentage of correct responses, response latency of correct choice responses and response speed were measured. Using this test, we examined the effects of three sedative drugs, diazepam $(0.25,1$ and $4 \mathrm{mg} / \mathrm{kg}$, i.g.), ethanol (0.5, 1 and $2 \mathrm{~g} / \mathrm{kg}$, i.g.), and pentobarbital $(0.25,1$ and 4 $\mathrm{mg} / \mathrm{kg}$, i.v.). Diazepam and pentobarbital lengthened response latency without significantly affecting the percentage of correct responses, response and response speed, suggesting selective disruptive effects on attentional performance. In contrast, ethanol at the high dose tested caused deterioration in all three measurements, which is thought to reflect a general sedative effect including motor impairment as reflected by lengthening response speed. It is suggested that the present behavioral test method could detect drug effects on attentional performance in monkeys and could be a useful tool for safety assessment in drug development.
\end{abstract}

Key words: Attentional performance, Choice reaction time task, Sedative drugs, Cynomolgus monkey

\section{INTRODUCTION}

In development of new medicinal products, assessment of drug effects on attention is important for evaluation of safety and/or therapeutic efficacy. Therapeutic efficacy of methylphenidate (Grizenko et al., 2006) and modafinil (Wigal et al., 2006) has been established in attention deficit hyperactivity disorder (ADHD). Attention deficit is also found in schizophrenia (Franke et al., 2007), mood disorder (Clark et al., 2002), Alzheimer's disease (Sebastian et al., 2006), and autism (Liss et al., 2006). In safety evaluation of drugs, several sedative drugs, such as benzodiazepines and alcohol have deteriorative effects on attention and can cause serious problems for daily activities such as driving (Verster et al., 2002; Kozená et al., 1995; Brookhuis et al., 1990; Schreckenberger et al., 2004; Arnedt et al., 2005).
However, attention is a complex cognitive function and establishing an appropriate analytical method in animals is not easy. The five choice serial reaction time task (5CSRTT) has been widely used to evaluate the effects of drugs on attention in rats (Robbins, 2002; Chudasama and Robbins, 2004). In this task, one of five holes in front of the animal is randomly illuminated for a short period. The animal has to make a nose poke into the illuminated hole within a limited time window in order to obtain a food reward. The 5CSRTT has been proven to be a useful paradigm for measuring sustained attention and divided attention in rats (Chudasama and Robbins, 2004). Using this task, the effects of various drugs have been tested. Nicotine (Hahn et al., 2002), an N-methyl- ${ }_{\mathrm{D}}$-aspartate (NMDA) NR2B antagonist traxopridil (Higgins et al., 2005), amphetamine and methylphenidate (Bizarro et al., 2004) have been demonstrated to improve performance of

Correspondence: Atsushi Fujiwara (E-mail: fujiwara@ina-research.co.jp) 
this task whereas such drugs as a kappa agonist (Shannon et al., 2007), MK-801 (Paine et al., 2007), and phencyclidine (Greco et al., 2005) are known to impair the performance of this task. In monkeys, Taffe et al. (2002a, 2002 b) reported that ketamine and (+/-)3,4-methylenedioxymethamphetamine impaired performance using a similar five-choice reaction time task. However, the effects of benzodiazepines, which are known to cause attention deficits in humans, have not been extensively studied in choice reaction time tasks.

Attentional performance requires integrative higher brain mechanisms which includes the prefrontal cortex (Lebedev et al., 2004), anterior cingulate (Richardson et al., 2008), and dorsal striatum (Balleine et al., 2007). Considering the involvement of these brain areas, preclinical evaluation using primates is certainly thought to be important. Recent electrophysiological studies using event-related potential also demonstrated similarity between the primate and human brain regarding attentional performance (Woodman et al., 2007).

In the present study, we have developed a behavioral test method to examine drug effects on attentional performance in monkeys. The basic character of this task is similar to the 5CSRTT. In this task, one of two cue lamps placed in front of a monkey is randomly illuminated and the monkey has to press the lever switch corresponding to the illuminated cue lamp to obtain food reinforcement. In order to characterize the drug effects, we set three measurements, choice accuracy, correct choice response latency and response speed. First, we examined the influence of the experimental parameters, duration of cue presentation length and intertrial interval, which are known to affect attentional performance (Mirza and Stolerman, 1998). Then we examined the effects of three sedative drugs, diazepam, ethanol and pentobarbital on attentional performance.

\section{MATERIALS AND METHODS}

All experimental procedures were approved and conducted in accordance with the Institutional Animal Care and Use Committee (IACUC) of Ina Research Inc., which is fully accredited by the Association for Assessment and Accreditation of Laboratory Animal Care International (AAALAC).

\section{Subjects}

Four female cynomolgus monkeys at the age of 3 years were used in the study. The monkeys weighed between 2.6 and $3.1 \mathrm{~kg}$ at the beginning of the experiment. None of the monkeys had a history of being used in behavio- ral pharmacological experiments. All monkeys were individually housed in stainless steel cages with high-pressure melamine facing plate walls $(68 \mathrm{~W} \times 86 \mathrm{D} \times 86 \mathrm{H} \mathrm{cm})$ in a monkey room maintained at approximately $25^{\circ} \mathrm{C}$, between 40 and $80 \%$ humidity, and on a 12-hr light/dark cycle (7:00AM - 7:00PM). In addition to banana-flavored pellets (P.J. Noyes Co., Lancaster, NH, USA) given during the experimental session, approximately $100 \mathrm{~g}$ of monkey chow (PS, Oriental Yeast Co., Ltd., Chiba, Japan) was given after the sessions. Drinking water was available ad libitum via an automatic water system installed in the individual home cages.

\section{Apparatus}

For the experimental sessions, the monkeys were restrained in a primate chair and placed in a wooden experimental chamber $(69 \mathrm{~W} \times 69 \mathrm{D} \times 114 \mathrm{H} \mathrm{cm})$. The right and left response levers were placed on the front wall of the chamber with respective red stimulus lights located above each lever. A food tray was placed approximately $5 \mathrm{~cm}$ below the middle of the two levers and a 300-mg banana-flavored pellet was delivered by an externally-mounted pellet dispenser (ENV-203-300IR, Med Associates Inc., Georgia, VT, USA). In addition, a house light was placed in the ceiling and a ventilation fan was placed on the sidewall of the chamber. The experimental events were controlled using a MED-PC system (Med Associates Inc.).

\section{Drugs}

Diazepam (Fabbrica Italiana Sintetici S.p.A., Vicenza, Italy) was suspended in $0.5 \%$ carboxymethylcellulose (Shin-Etsu Chemical Co., Ltd., Tokyo, Japan) solution. Ethanol (special grade, Wako Pure Chemical industries, Ltd., Osaka, Japan) was diluted with distilled water (Otsuka Pharmaceutical Factory, Inc., Tokushima, Japan). Sodium pentobarbital (Nembutal ${ }^{\circledR}$, Dainippon Sumitomo Pharma Co., Ltd., Osaka, Japan) was dissolved in sterilized physiological saline (Otsuka Pharmaceutical Factory, Inc.) and dosing solutions were filtered through a $0.22 \mu \mathrm{m}$ MILLEX-GS (Millipore Corporation Ltd., Billerica, MA, USA). Diazepam and ethanol were administered intragastrically $1 \mathrm{hr}$ before testing in a volume of $1 \mathrm{ml} / \mathrm{kg}$. Pentobarbital was intravenously administered $15 \mathrm{~min}$ before testing in a volume of $0.25 \mathrm{ml} / \mathrm{kg}$.

\section{Training}

First, a discrete trial type of lever press training was given. In each session of this training, one of two levers was introduced into the chamber and in each trial, a cue lamp above this lever was illuminated for up to $30 \mathrm{sec}$. 
Attentional performance in cynomolgus monkeys

Initially, the monkeys were required to press the lever within this $30 \mathrm{sec}$ time window. A lever press resulted in delivery of a food pellet and the lamp turned off for $10 \mathrm{sec}$ and then the next trial began. Fifty such trials were given daily for the left and right levers alternatively. Once a stable response was established, the number of lever press responses to obtain a food pellet was gradually increased to $2,3,5,7,10$ and finally 30 , where 30 lever press responses were required to obtain a food pellet. The cue lamp was turned on until 30 responses were obtained. Then, two-lever discrimination training was started. In this stage, two response levers were introduced and one of the cue lamps above each lever was randomly illuminated for up to $30 \mathrm{sec}$. Thirty lever press responses to the illuminated side were reinforced with a food pellet. The next trial began after a $10 \mathrm{sec}$ interval (intertrial interval: ITI). Fifty such trials were given daily. Monkeys were trained on this schedule for one month until they were able to receive 50 pellets within $30 \mathrm{~min}$ and then the ITI was varied. The ITI was randomly selected from 5 , $10,15,20,25,30,35,40,45$ or $50 \mathrm{sec}$. When the percentage of correct responses (CR\%) exceeded $90 \%$ for three consecutive days, the duration of the cue lamp illumination was gradually decreased to 5.0, 2.0 and finally 1.5 sec per trial every 2 weeks. If the monkey failed to make the first responses within the $1.5 \mathrm{sec}$ lamp presentation, the omission was recorded and the lamp turned off and an ITI for the next trial was started. Training was continued until the number of omission trials of less than $10 \%$ of the daily trials and the $\mathrm{CR} \%$ of the first choice in each trial exceeded $90 \%$ for three consecutive days. The CR\% of the first choice was defined as the number of the first correct responses divided by the total number of the first correct and error responses. The left side lever was assigned as the correct side for half of the daily trials and the right side was assigned as the correct side in other half of the trials. Moreover, each ITI duration was assigned once per ten trials.

\section{Behavioral testing}

After the above criteria were met, the influences of the ITI and cue presentation duration on attentional performance were each tested. In the former tests, the ITI duration was increased to 5, 50 and $100 \mathrm{sec}$ and the cue presentation duration was fixed at $5 \mathrm{sec}$. The test schedule was $5 \mathrm{sec}$ of ITI on the first day, $50 \mathrm{sec}$ on the second day and $100 \mathrm{sec}$ on the third day. In the later tests, the cue presentation duration was decreased to 5.0, 2.0, 1.5 and $1.0 \mathrm{sec}$ and the ITIs randomly occurred as described above. The test schedule was $5.0 \mathrm{sec}$ of cue duration on the first day, $2.0 \mathrm{sec}$ on the second day, $1.5 \mathrm{sec}$ on the third day and $1.0 \mathrm{sec}$ on the fourth day.

\section{Drug testing}

After completion of behavioral tests, training using varying ITIs from 5 to $50 \mathrm{sec}$, as described above, and $1.5 \mathrm{sec}$ cue duration was resumed. When confirmation of training criteria was again obtained, the drug testing was started. The tested drugs and their doses were diazepam at 0.25 , 1 and $4 \mathrm{mg} / \mathrm{kg}$, i.g., ethanol at 0.5, 1 and $2 \mathrm{~g} / \mathrm{kg}$, i.g. and pentobarbital at $0.25,1$ and $4 \mathrm{mg} / \mathrm{kg}, \mathrm{i} . \mathrm{v}$. . The test schedule was vehicle on the first day, low dose on the second day, mid-dose on the third day and high dose on the fourth day and was conducted once every 2 weeks. During the test, training was given once daily except weekend and percentage of the correct response above $90 \%$ was confirmed on the training day before drug test.

\section{Measurement}

Three measurements were calculated: 1) The percentage of $\mathrm{CR} \%$ : The definition was the same as described in the training section. This value could be mainly regarded as a measure of general cognitive performance. 2) Response latency: The time from the onset of the cue lamp to first correct response of the successful trials was recorded. Latency for error trials was not included in the analysis. This value was considered as a major measurement of attentional performance. 3) Response speed: The time required for completion of 30 correct responses was recorded. Then, dividing the time by 30 , the number of responses per second was calculated and denoted as the response speed. This value was regarded mainly as a measure of motor performance.

\section{Data analysis}

Behavioral test data were analyzed by Dunnett's test. For drug test data, first homogeneity of variance was analyzed by Bartlett's test. If homogeneity was confirmed, the dose response was analyzed by Williams test. If homogeneity was not confirmed, the dose response was analyzed by the Shirley-Williams test. The significant level was set at $\mathrm{p}<0.05$ (two-tailed).

\section{RESULTS}

\section{Influence of ITI}

The $\mathrm{CR} \%$, the latencies of the correct responses and response speed under various cue lamp durations are shown in Fig. 1. The figure shows the means and the standard deviations. The CR\% at $100 \mathrm{sec}$ of ITI was significantly lower than that at $5 \mathrm{sec}$. The latencies of correct responses at 50 and $100 \mathrm{sec}$ of ITI were significantly longer than that at $5 \mathrm{sec}$. No significant influence of ITI was shown on response speed. 


\section{A. Fujiwara et al.}

\section{Influence of cue lamp duration}

$\mathrm{The} \mathrm{CR} \%$, the latencies of the correct responses and the response speed under various cue lamp durations are shown in Fig. 2 in the same manner as in Fig. 1. As shown in the figure, the $\mathrm{CR} \%$ of the correct responses at the cue duration of $1.0 \mathrm{sec}$ was significantly lower than those at the duration of $5.0 \mathrm{sec}$. This means that when the duration of the cue lamp was too short, the choice became inaccurate. Response latency and response speed were not affected by the cue lamp duration.

\section{Effects of drugs}

Although it was revealed that using long ITI caused deterioration of attentional performance, when the ITI was randomized at a range of 5 to $50 \mathrm{sec}$, no systematic influence of the ITI was found in training sessions preceding the drug tests. The numbers of omission trials showed no systematic change due to the test drugs and was less than $10 \%$ of total trials even at the highest doses of each test drug. Thus, this measure is not described here. The mean CR\%s at each dose of each drug are shown in Fig. 3 with the standard deviation. In all the three vehicle tests, the mean $\mathrm{CR} \%$ s were around 97 to $100 \%$, showing that stable correct choice responses were maintained. With diazepam, no effect was found at 0.25 and $1 \mathrm{mg} / \mathrm{kg}$. The $\mathrm{CR} \%$ decreased to $87 \%$ at $4 \mathrm{mg} / \mathrm{kg}$, but due to the large individual differences (76-100\%), there was no significant difference from the vehicle control. Sodium pentobarbital produced no dose-dependent change on the $\mathrm{CR} \%$. Even at the high dose $(4 \mathrm{mg} / \mathrm{kg})$, the mean $\mathrm{CR} \%$ was compara-
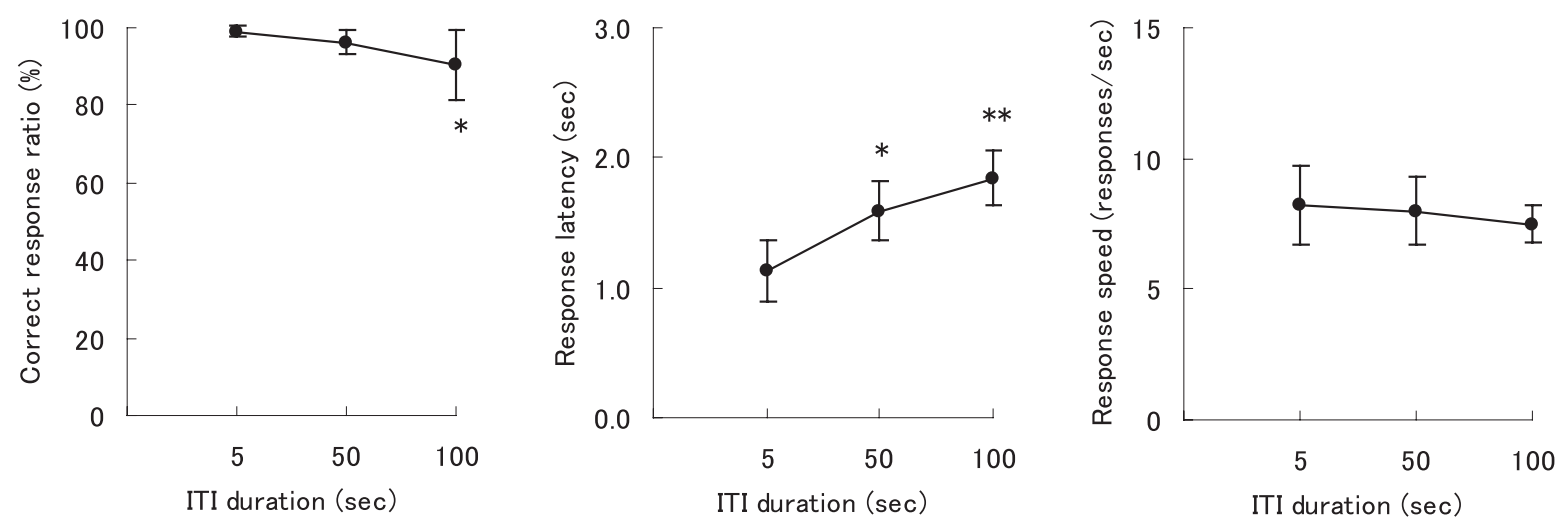

Fig. 1. Influence of intertrial intervals on performance of two-lever choice reaction task in cynomolgus monkeys. Mean percentages of correct responses, response latency and response speed are shown with the standard deviation. $*: \mathrm{p}<0.05, * *: \mathrm{p}<0.01$ vs performance at $5 \mathrm{sec}$ interval by Dunnett's test.
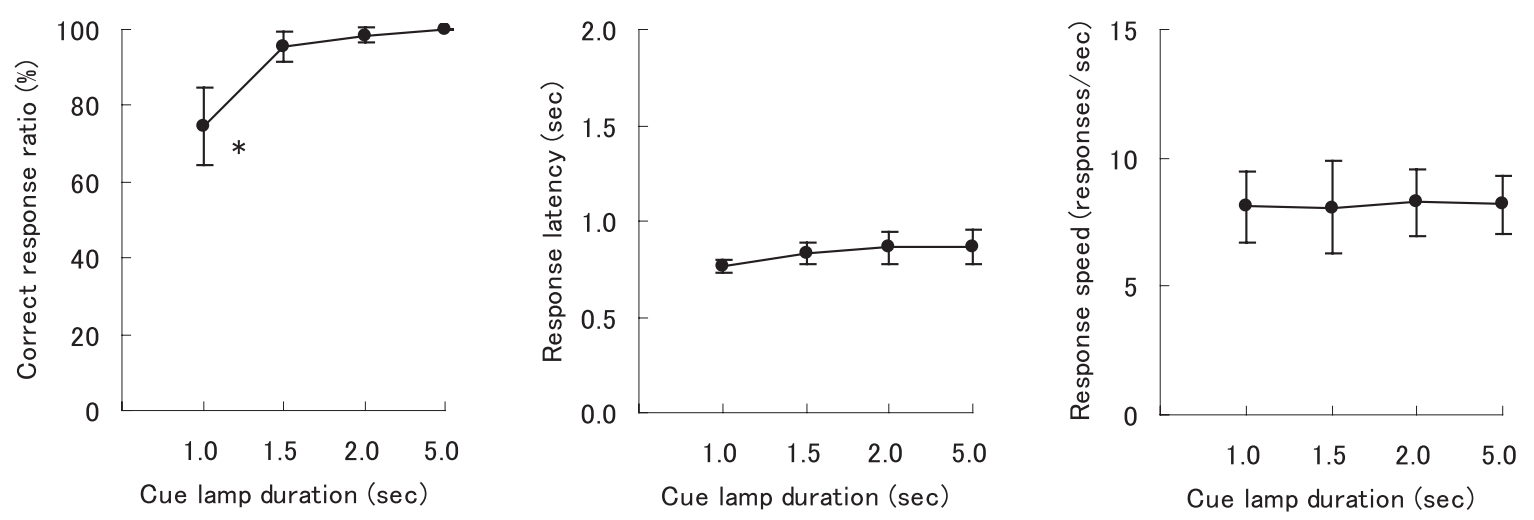

Fig. 2. Influence of cue lamp duration on performance of two-lever choice reaction task in cynomolgus monkeys. Mean percentages of correct responses, response latency, and response speed are shown with the standard deviation. $*: \mathrm{p}<0.05$ vs performance at $5 \mathrm{sec}$ duration by Dunnett's test. 
Attentional performance in cynomolgus monkeys

ble to that at the vehicle test. When ethanol at $2 \mathrm{~g} / \mathrm{kg}$ was administered, the $\mathrm{CR} \%$ was significantly reduced in comparison with that of the vehicle control.

The mean latencies of the correct choice responses in each test are shown in Fig. 4 with the standard deviation. A dose-dependent increase in response latency was observed for all three drugs tested. In the vehicle tests, latency was around 0.7 to $0.8 \mathrm{sec}$, with a range of 0.63 to $0.83 \mathrm{sec}$. Intragastric administration of diazepam at 1 $\mathrm{mg} / \mathrm{kg}$ increased mean latency to $0.87 \mathrm{sec}$ with a range of
0.86 to $0.92 \mathrm{sec}$. At $4 \mathrm{mg} / \mathrm{kg}$, latency was further significantly increased to $1.00 \mathrm{sec}$ (range 0.91 to $1.10 \mathrm{sec}$ ). With sodium pentobarbital, a significant increase was found only at the high dose $(4 \mathrm{mg} / \mathrm{kg})$. With ethanol, a significant increase compared with vehicle control was found at $2 \mathrm{~g} / \mathrm{kg}$. The mean latency at this dose was $0.89 \mathrm{sec}$ with a range of 0.84 to $1.00 \mathrm{sec}$.

The mean response speeds and standard deviations are shown in Fig. 5. The response speed in the vehicle test was around 8 to 10 responses per second (range 7.1 to
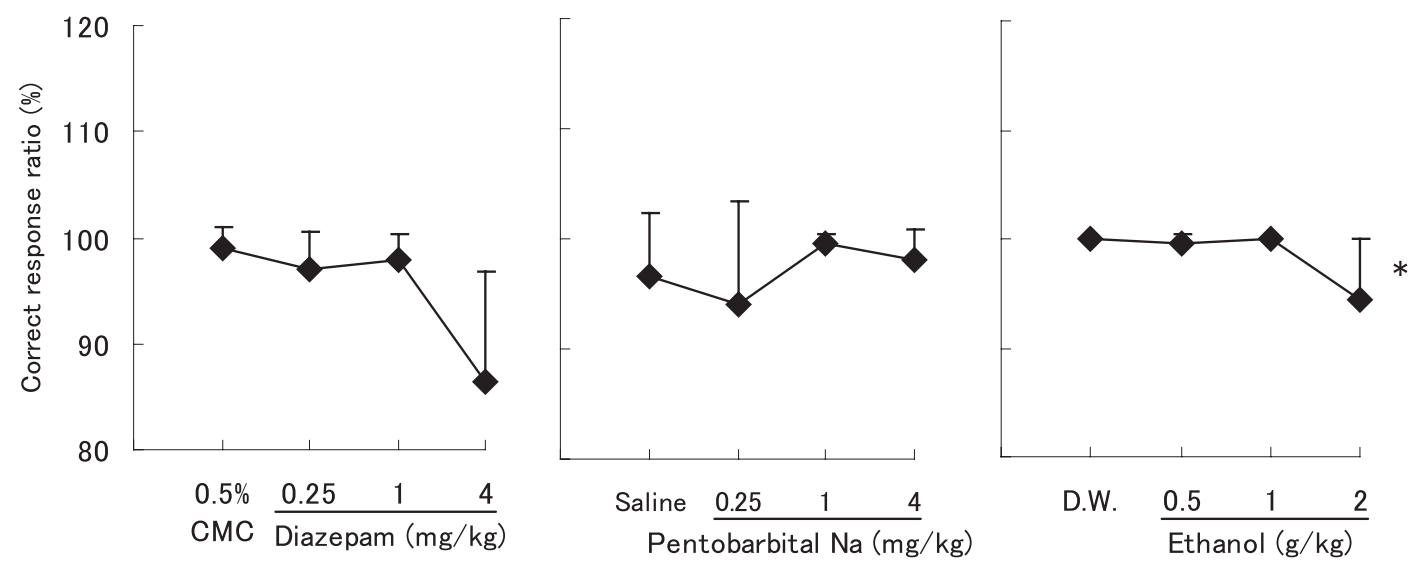

Fig. 3. Effects of diazepam (left), sodium pentobarbital (middle), and ethanol (right) on percentages of correct response in twolever choice reaction task in cynomolgus monkeys. Mean percentages of correct responses of four monkeys are shown with standard deviation.

*: $p<0.05$ vs vehicle control by Shirley-Williams test.
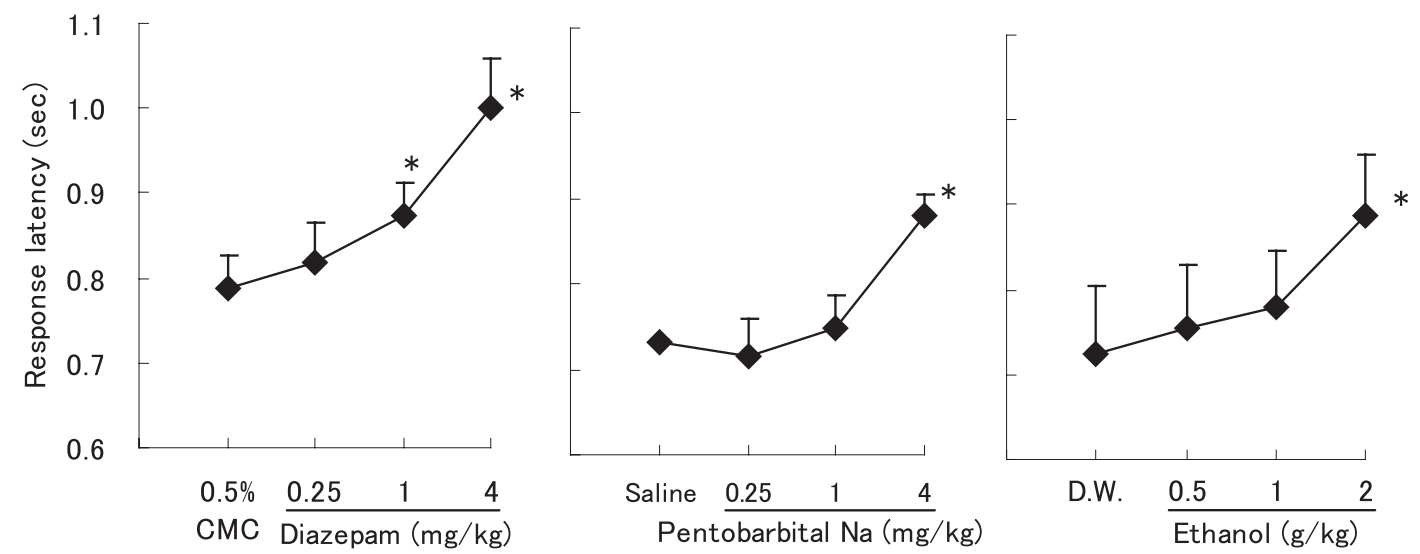

Fig. 4. Effects of diazepam (left), sodium pentobarbital (middle), and ethanol (right) on response latency in two-lever choice reaction task in cynomolgus monkeys. Mean latency, i.e., the time elapsed from the onset of the cue lamp until the first correct response of four monkeys are shown with the standard deviation. Latency for error trials was not included in this measure.

*: $\mathrm{p}<0.05$ vs the vehicle control by Williams or Shirley-Williams test. 
A. Fujiwara et al.
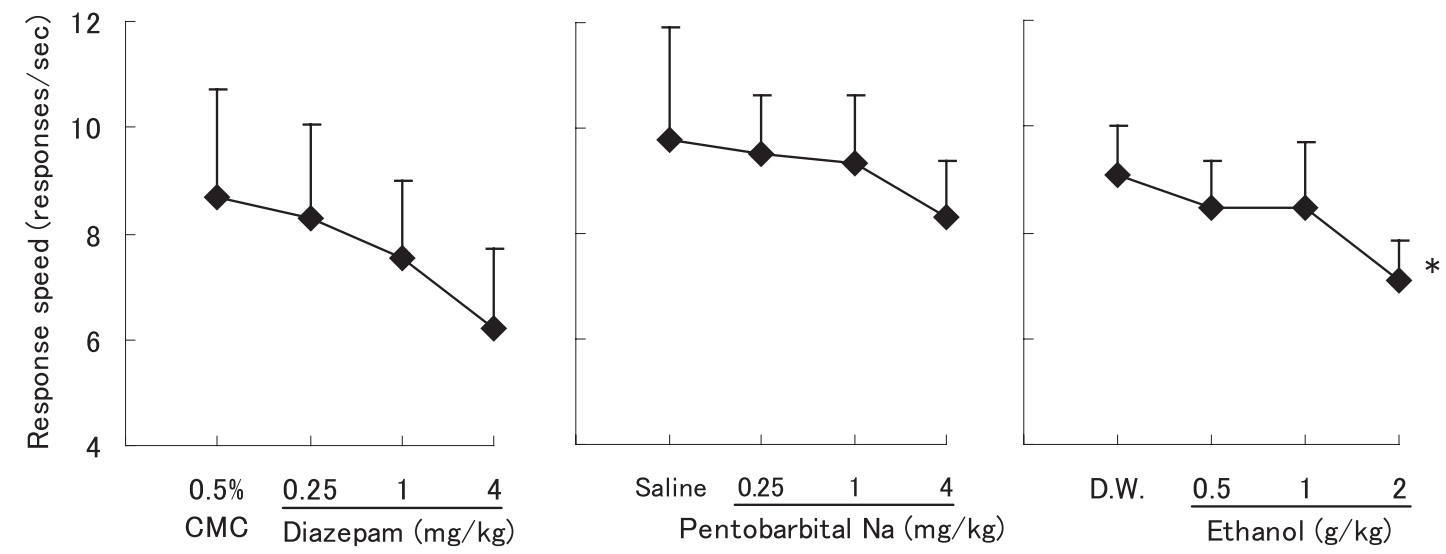

Fig. 5. Effects of diazepam (left), sodium pentobarbital (middle), and ethanol (right) on response speed in two-lever choice reaction task in cynomolgus monkeys. Response speed was defined as the number of lever-press responses per second. Mean response speed of four monkeys are shown with the standard deviation.

$*: \mathrm{p}<0.05$ vs the vehicle control by Williams test.

13.0, overall mean 9.2 responses per second). That means almost all the monkeys completed 30 lever presses within about $3.3 \mathrm{sec}$. Diazepam dose-dependently slowed down the response speed but there was no significant difference even at the high dose $(4 \mathrm{mg} / \mathrm{kg})$. With sodium pentobarbital, a slowing of response speed was not apparent. Ethanol at $2 \mathrm{~g} / \mathrm{kg}$ caused significant slowing of response speed compared with vehicle control.

\section{DISCUSSION}

In the present experiment, we have attempted to develop a behavioral test method to evaluate drug effects on attentional performance. This method was a visual choice reaction time task and is considered to correspond to human vigilance tasks which are known to be influenced by chemical substances and mental disorders (Rohrbaugh et al., 1988; Nestor et al., 1990; Schneider et al., 1999; Swaab-Barneveld et al., 2000).

We used female monkeys in this experiment. Although hormonal influences on behavior and drug sensitivity should not be neglected, no overt behavioral signs due to menstruation were noted during the course of the experiment. Female monkeys are known to be more sensitive to drugs of abuse than males (Lynch, 2006; Roth et al., 2004; Carroll et al., 2004). Thus, using female monkeys for safety assessment is considered to be favorable in some cases.

Basic behavioral characteristics of the present twolever choice task were similar to those known in the 5CSRTT in rats. Namely, too short a cue presentation and too sparse a trial worsened the performance (Mirza and Stolerman, 1998; Hahn et al., 2002). Thus, it was considered that the present task performance preserves a similar trend as the 5CSRTT and might be a valid task to test visual sustained attention. Using randomly selected ITI might be useful to maintain sustained attention for visual cues.

The three drugs, diazepam, pentobarbital and ethanol, used in the present study share similar sedative properties. As expected, these drugs caused deterioration in performance of the present task. However, at the same time, several differences between the drugs were also noted. Diazepam and pentobarbital lengthened response latency without affecting percentage of correct responses. In contrast, ethanol at the effective dose lengthened response speed.

The deteriorative effect of diazepam on attentional performance is in line with that in the literature for humans (Kelland and Lewis, 1996; Kozená et al., 1995; UnrugNeervoort et al., 1992; Koelega, 1989). In the present experiment, diazepam significantly affected attentional performance at $1 \mathrm{mg} / \mathrm{kg}$ and above. Based on the findings of the effects of diazepam using a multiple cognitive test battery (Schulze et al., 1989), it was revealed that the sensitivity of the present attention task is less than that of a time estimation task, comparable to a working memory task, and more sensitive than learning and motivational tasks.

The effect of pentobarbital was similar to diazepam. Several studies have revealed the effects of pentobarbital causing deterioration in cognitive functions in mon- 
Attentional performance in cynomolgus monkeys

keys. But most have shown the effect at doses that impair motor function (Baron and Wenger, 2001; Ferguson and Paule, 1993). Since the high dose of pentobarbital (4 mg/ $\mathrm{kg}$ ) lengthened the response latency but not the response speed, the effects on attention and motor function could be detected separately using the present task.

With ethanol, the disruptive effect on attentional performance was not thought to be selective because the effect was apparent only at $2 \mathrm{~g} / \mathrm{kg}$ and this dose is enough to induce gross sedation (Yanagita and Takahashi, 1973). Although ethanol has been reported to impair sustained attention in rats (Givens, 1997), in a human study it was questioned whether the effect is selective for attention or not (Koelega, 1995). Moreover, also in a human study, the effect of ethanol in causing deterioration in vigilance was apparent only as subjective feelings, such as "dizziness" or "a high" after taking ethanol (Liguori et al., 1999). Based on the present findings, we think the effect of ethanol on attention is not selective but is mixed with a motor-impairment component.

To further investigate the validity and usefulness of this task and to establish it as a testing method for the assessment of attention in monkeys, it seems to be important to test effects of such manipulations as sleep deprivation (van Vliet et al., 2008), fatigue (Ahsberg et al., 2000), and aging (Mani et al., 2005) on the present task and to incorporate this experiment into a cognitive test battery using monkeys (Paule, 1990).

In conclusion, drug effects on attentional performance in monkeys could be detected by the present two-lever choice reaction time task. Evaluation of drug effects on attention using monkeys is an important and useful tool in safety assessment of chemical substances.

\section{ACKNOWLEDGMENTS}

The authors thank Mr. Takahiro Ootsuka and Mr. Mitsuru Hoshino for providing technical assistance.

\section{REFERENCES}

Ahsberg, E., Gamberale, F. and Gustafsson, K. (2000): Perceived fatigue after mental work: an experimental evaluation of a fatigue inventory. Ergonomics, 43, 252-268.

Arnedt, J.T., Owens, J., Crouch, M., Stahl, J. and Carskadon, M.A. (2005): Neurobehavioral performance of residents after heavy night call vs after alcohol ingestion. JAMA, 294, 1025-1033.

Balleine, B.W., Delgado, M.R. and Hikosaka, O. (2007): The role of the dorsal striatum in reward and decision-making. J. Neurosci., 27, 8161-8165.

Baron, S.P. and Wenger, G.R. (2001): Effects of drugs of abuse on response accuracy and bias under a delayed matching-to-sample procedure in squirrel monkeys. Behav. Pharmacol., 12, 247-256.
Bizarro, L., Patel, S., Murtagh, C. and Stolerman, I.P. (2004): Differential effects of psychomotor stimulants on attentional performance in rats: nicotine, amphetamine, caffeine and methylphenidate. Behav. Pharmacol., 15, 195-206.

Brookhuis, K.A., Volkerts, E.R. and O'Hanlon, J.F. (1990): Repeated dose effects of lormetazepam and flurazepam upon driving performance. Eur. J. Clin. Pharmacol., 39, 83-87.

Carroll, M.E., Lynch, W.J., Roth, M.E., Morgan, A.D. and Cosgrove, K.P. (2004): Sex and estrogen influence drug abuse. Trends. Pharmacol. Sci., 25, 273-279.

Chudasama, Y., Baunez, C. and Robbins, T.W. (2003): Functional disconnection of the medial prefrontal cortex and subthalamic nucleus in attentional performance: evidence for corticosubthalamic interaction. J. Neurosci., 23, 5477-5485.

Chudasama, Y. and Robbins, T.W. (2004): Psychopharmacological approaches to modulating attention in the five-choice serial reaction time task: implications for schizophrenia. Psychopharmacology (Berl), 174, 86-98.

Clark, L., Iversen, S.D. and Goodwin, G.M. (2002): Sustained attention deficit in bipolar disorder. Br. J. Psychiatry, 180, 313-319.

Dalley, J.W., Theobald, D.E., Berry, D., Milstein, J.A., Lääne, K., Everitt, B.J. and Robbins, T.W. (2005): Cognitive sequelae of intravenous amphetamine self-administration in rats: evidence for selective effects on attentional performance. Neuropsychopharmacology, 30, 525-537.

Ferguson, S.A. and Paule, M.G. (1993): Acute effects of pentobarbital in a monkey operant behavioral test battery. Pharmacol. Biochem. Behav., 45, 107-116.

Franke, C., Reuter, B., Schulz, L. and Kathmann, N. (2007): Schizophrenia patients show impaired response switching in saccade tasks. Biol. Psychol., 76, 91-99.

Givens, B. (1997): Effect of ethanol on sustained attention in rats. Psychopharmacology (Berl), 129, 135-140.

Greco, B., Invernizzi, R.W. and Carli, M. (2005): Phencyclidineinduced impairment in attention and response control depends on the background genotype of mice: reversal by the mGLU(2/3) receptor agonist LY379268. Psychopharmacology (Berl), 179, 68-76.

Grizenko, N., Bhat, M., Schwartz, G., Ter-Stepanian, M. and Joober, R. (2006): Efficacy of methylphenidate in children with attention-deficit hyperactivity disorder and learning disabilities: a randomized crossover trial. J. Psychiatry Neurosci., 31, 46-51.

Hahn, B., Shoaib, M. and Stolerman, I.P. (2002): Nicotine-induced enhancement of attention in the five-choice serial reaction time task: the influence of task demands. Psychopharmacology (Berl), 162, 129-137.

Higgins, G.A., Ballard, T.M., Enderlin, M., Haman, M. and Kemp, J.A. (2005): Evidence for improved performance in cognitive tasks following selective NR2B NMDA receptor antagonist pretreatment in the rat. Psychopharmacology (Berl), 179, 85-98.

Kelland, D.Z. and Lewis, R.F. (1996): The Digit Vigilance Test: reliability, validity, and sensitivity to diazepam. Arch. Clin. Neuropsychol., 11, 339-344.

Koelega, H.S. (1989): Benzodiazepines and vigilance performance: a review. Psychopharmacology (Berl), 98, 145-156.

Koelega, H.S. (1995): Alcohol and vigilance performance: a review. Psychopharmacology (Berl), 118, 233-249.

Kozená, L., Frantik, E. and Horváth, M. (1995): Vigilance impairment after a single dose of benzodiazepines. Psychopharmacology (Berl), $119,39-45$.

Lebedev, M.A., Messinger, A., Kralik, J.D. and Wise, S.P. (2004): Representation of attended versus remembered locations in pre- 
frontal cortex. PLoS Biol., 2, e365

Liguori, A., D’Agostino, R.B. Jr., Dworkin, S.I., Edwards, D. and Robinson, J.H. (1999): Alcohol effects on mood, equilibrium, and simulated driving. Alcohol. Clin. Exp. Res., 23, 815-821.

Liss, M., Saulnier, C., Fein, D. and Kinsbourne, M. (2006): Sensory and attention abnormalities in autistic spectrum disorders. Autism, 10, 155-172.

Lynch, W.J. (2006): Sex differences in vulnerability to drug selfadministration. Exp. Clin. Psychopharmacol., 14, 34-41.

Mani, T.M., Bedwell, J.S. and Miller, L.S. (2005): Age-related decrements in performance on a brief continuous performance test. Arch. Clin. Neuropsychol., 20, 575-586.

McDowd, J.M. (2007): An overview of attention: behavior and brain. J. Neurol. Phys. Ther., 31, 98-103.

Mirza, N.R. and Stolerman, I.P. (1998): Nicotine enhances sustained attention in the rat under specific task conditions. Psychopharmacology (Berl), 138, 266-274.

Nestor, P.G., Faux, S.F., McCarley, R.W., Shenton, M.E. and Sands, S.F. (1990): Measurement of visual sustained attention in schizophrenia using signal detection analysis and a newly developed computerized CPT task. Schizophr. Res., 3, 329-332.

Paine, T.A., Tomasiewicz, H.C., Zhang, K. and Carlezon, W.A.Jr. (2007): Sensitivity of the five-choice serial reaction time task to the effects of various psychotropic drugs in Sprague-Dawley rats. Biol. Psychiatry, 62, 687-693.

Paule, M.G. (1990): Use of the NCTR Operant Test Battery in nonhuman primates. Neurotoxicol. Teratol., 12, 413-418.

Richardson, A.G., Lassi-Tucci, G., Padoa-Schioppa, C. and Bizzi, E. (2008): Neuronal activity in the cingulate motor areas during adaptation to a new dynamic environment. J. Neurophysiol., 99, 1253-1266.

Robbins, T.W. (2002): The 5-choice serial reaction time task: behavioural pharmacology and functional neurochemistry. Psychopharmacology (Berl), 163, 362-380.

Rohrbaugh, J.W., Stapleton, J.M., Parasuraman, R., Frowein, H.W., Adinoff, B., Varner, J.L., Zubovic, E.A., Lane, E.A., Eckardt, M.J. and Linnoila, M. (1988): Alcohol intoxication reduces visual sustained attention. Psychopharmacology (Berl), 96, 442-446.

Roth, M.E., Cosgrove, K.P. and Carroll, M.E. (2004): Sex differences in the vulnerability to drug abuse: a review of preclinical studies. Neurosci. Biobehav. Rev., 28, 533-546.

Schneider, U., Bevilacqua, C., Jacobs, R., Karst, M., Dietrich, D.E., Becker, H., Müller-Vahl, K.R., Seeland, I., Gielsdorf, D., Schedlowski, M. and Emrich, H.M. (1999): Effects of fentanyl and low doses of alcohol on neuropsychological performance in healthy subjects. Neuropsychobiology, 39, 38-43.

Schreckenberger, M., Amberg, R., Scheurich, A., Lochmann, M., Tichy, W., Klega, A., Siessmeier, T., Gründer, G., Buchholz, H.G., Landvogt, C., Stauss, J., Mann, K., Bartenstein, P. and Urban, R. (2004): Acute alcohol effects on neuronal and attentional processing: striatal reward system and inhibitory sensory interactions under acute ethanol challenge. Neuropsychopharmacology, 29, 1527-1537.

Schulze, G.E., Slikker, W.Jr. and Paule, M.G. (1989): Multiple behavioral effects of diazepam in rhesus monkeys. Pharmacol. Biochem. Behav., 34, 29-35.

Sebastian, M.V., Menor, J. and Elosua, M.R. (2006): Attentional dysfunction of the central executive in $\mathrm{AD}$ : evidence from dual task and perseveration errors. Cortex, 42, 1015-1020.

Shannon, H.E., Eberle, E.L., Mitch, C.H., McKinzie, D.L. and Statnick, M.A. (2007): Effects of kappa opioid receptor agonists on attention as assessed by a 5 -choice serial reaction time task in rats. Neuropharmacology, 53, 930-941.

Swaab-Barneveld, H., de Sonneville, L., Cohen-Kettenis, P., Gielen, A., Buitelaar, J. and Van Engeland, H. (2000): Visual sustained attention in a child psychiatric population. J. Am. Acad. Child. Adolesc. Psychiatry, 39, 651-659.

Taffe, M.A., Weed, M.R., Gutierrez, T., Davis, S.A. and Gold, L.H. (2002a): Differential muscarinic and NMDA contributions to visuo-spatial paired-associate learning in rhesus monkeys. Psychopharmacology (Berl), 160, 253-262.

Taffe, M.A., Davis, S.A., Gutierrez, T. and Gold, L.H. (2002b): Ketamine impairs multiple cognitive domains in rhesus monkeys. Drug Alcohol Depend., 68, 175-187.

Unrug-Neervoort, A., van Luijtelaar, G. and Coenen, A. (1992): Cognition and vigilance: differential effects of diazepam and buspirone on memory and psychomotor performance. Neuropsychobiology, 26, 146-150.

van Vliet, S.A., Jongsma, M.J., Vanwersch, R.A., Olivier, B. and Philippens, I.H. (2008): Efficacy of caffeine and modafinil in counteracting sleep deprivation in the marmoset monkey. Psychopharmacology (Berl), 197, 59-66.

Verster, J.C., Volkerts, E.R. and Verbaten, M.N. (2002): Effects of alprazolam on driving ability, memory functioning and psychomotor performance: a randomized, placebo-controlled study. Neuropsychopharmacology, 27, 260-269.

Wigal, S.B., Biederman, J., Swanson, J.M., Yang, R. and Greenhill, L.L. (2006): Efficacy and safety of modafinil film-coated tablets in children and adolescents with or without prior stimulant treatment for attention-deficit/hyperactivity disorder: pooled analysis of 3 randomized, double-blind, placebo-controlled studies. Prim. Care Companion. J. Clin. Psychiatry, 8, 352-360.

Wingen, M., Kuypers, K.P. and Ramaekers, J.G. (2007): The role of 5-HT1a and 5-HT2a receptors in attention and motor control: a mechanistic study in healthy volunteers. Psychopharmacology (Berl), 190, 391-400

Woodman, G.F., Kang, M.S., Rossi, A.F. and Schall, J.D. (2007): Nonhuman primate event-related potentials indexing covert shifts of attention. PNAS, 104, 15111-15116.

Yanagita, T. and Takahashi, S. (1973): Dependence liability of several sedative-hypnotic agents evaluated in monkeys. J. Pharmacol. Exp. Ther., 185, 307-316. 